\title{
Transcatheter occlusion of a Blalock-Taussig shunt with a detachable balloon in a child
}

\author{
J F REIDY, E BAKER, M TYNAN \\ From Departments of Radiology and Paediatric Cardiology, Guy's Hospital, London
}

SUMMARY A case of transcatheter occlusion of a Blalock-Taussig shunt with a detachable silicone filled balloon is described.

This 11 year old boy had previously had a repair of tetralogy of Fallot together with ligation of a large Blalock-Taussig shunt. Though there was a good surgical result, the shunt proved to be incompletely closed leaving a significant left to right shunt. As an alternative to a further operation a silicone filled balloon was detached in the Blalock-Taussig shunt and this successfully closed the fistula.

In recent years there has been a dramatic increase in the number of embolisation or occlusion procedures performed by transcatheter techniques. Most of these have been in end arteries and many different occlusion techniques are available.

Arteriovenous fistulae and other fistulous vascular abnormalities present a more difficult problem. They are often large, may be quite short, and are usually associated with a high blood flow. The occlusion then must be very precise and with no risk of distal embolisation. In this situation detachable balloons have proved to be valuable and the main experience has been in neuroradiology.

Until recently, surgery was the only treatment for significant vascular fistulae and malformations related to the heart. We present a case of transcatheter occlusion of a large Blalock-Taussig shunt which, to our knowledge, is the first published case of successful occlusion with a detachable balloon.

\section{Case report}

A 3 month old baby boy was found to have a murmur which was discovered during a routine examination. He was asymptomatic and not cyanosed. Clinically he was thought to have pulmonary atresia or tetralogy of Fallot, with a persistent ductus arteriosus, and he was initially managed conservatively. At 7 years of age he was becoming increasingly breathless on exertion and had developed increasing cyanosis, but had never had hypercyanotic spells. Cardiac catheterisation was performed and showed tetralogy of Fallot with a single systemic to pulmonary collateral from the arch of the aorta to the left pulmonary artery.

Six months after catheterisation a conventional left Blalock-Taussig shunt was created and the collateral was ligated. He made a good recovery, exercise tolerance improved, and cyanosis decreased. When he was recatheterised two years later, the diagnosis was confirmed and the Blalock-Taussig shunt was patent. Repair of the cardiac lesion was performed, and the left subclavian artery, which was moderately dilated, was ligated at its origin. Initially he made a good recovery, but three weeks after operation he developed severe heart failure and medical treatment had to be started. Six months after operation a continuous murmur was heard again over the left side of the chest. A radionuclide angiogram showed that there was a large left to right shunt flowing predominantly to the left lung. At a third cardiac catheterisation a year after operation, cineangiography showed that the Blalock-Taussig shunt was still patent (Fig. 1).

In view of the patency of the Blalock-Taussig shunt after surgical ligation transcatheter occlusion was considered as an alternative to a further operation. The only technique applicable and available was the Debrun latex balloon embolisation system.* Before

^Ingenor Medical, Paris. 


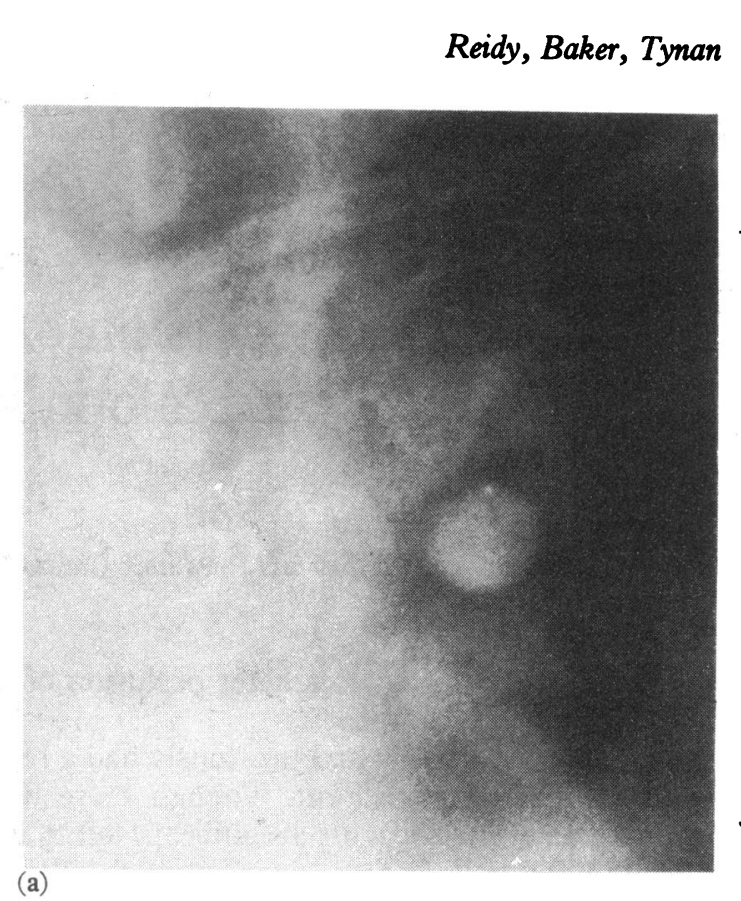

Fig. 1 Injection into the Blalock shunt (catheter via right sided aortic arch). Note the dilatation of the subclavian and the stenosis where it anastomoses with the left pulmonary artery.

the embolisation three of the largest size latex balloons were prepared and tested. The maximum size of inflation was $20 \mathrm{~mm} \times 12 \mathrm{~mm}$ diameter.

A further catheterisation was performed five months later via a right femoral arteriotomy. Selective injection into the left Blalock-Taussig shunt again showed it to be patent, but considerably dilated with a stenosis at the site of anastomosis with the left pulmonary artery. The coaxial balloon system was inserted via a $9 \mathrm{~F}$-non-tapered Teflon catheter placed in the Blalock-Taussig shunt. When inflation of the balloon with dilute contrast medium showed that it occluded the shunt, the contrast medium was aspirated and replaced with an equal volume of a mixture of the two silicone modified reactive monomers (Ingenol $A$ and $B^{\star}$ ). After about 20 minutes when polymerisation and vulcanisation were adjudged to have occurred, the balloon was detached with gentle traction. Injection into the proximal shunt showed it to be occluded (Fig. 2a and b).

He was discharged two days after the procedure and when seen one month later he was well and was able to stop all treatment. The continuous murmur was no longer heard.

\section{Discussion}

More than 10 years ago a method of non-surgical closure of the ductus arteriosus was described. ${ }^{1}$ There are technical problems in occluding such a short non-end artery, and as operation is so safe and straightforward

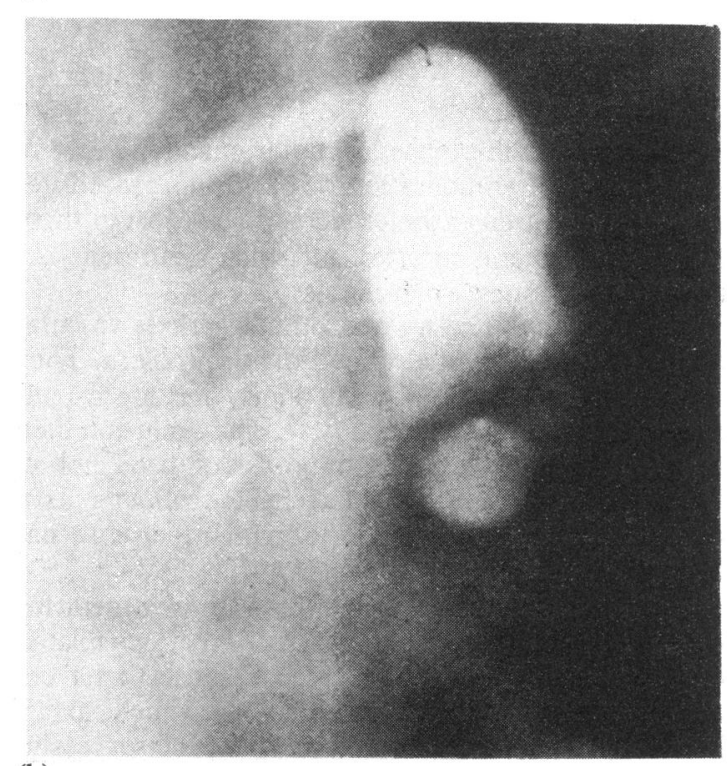

(b)

Fig. 2 Post-balloon occlusion. (a) Note the rounded opacity produced by a small contrast residue in the balloon. The metal marker in the balloon is seen at "12 o'clock". (b) Injection into the mouth of the Blalock shunt shows complete occlusion and an ooal radiolucent defect caused by the silicone filled balloon.

this and other such methods have not supplanted it. Apart from this, in congenital heart disease, nonsurgical embolisation or occlusion techniques have $\stackrel{\square}{\square}$ been used in only a few cases and these only in the last few years. 
The first case of embolic occlusion of a BlalockTaussig shunt was described in a child of 4 years. $^{2}$ This child had excessive pulmonary blood flow. The authors of the report cite the advantages of inflatable detachable balloons especially in the ability to control and adjust their position. They considered the Blalock-Taussig shunt in their case to be too wide and too short properly to position a balloon and they therefore used a modified and shortened minicoil. The advantages of balloon embolisation were emphasised by the fact that the first coil used passed into the left lower lobe pulmonary artery. A second coil was required to occlude the shunt successfully.

The Blalock-Taussig shunt in our patient was considerably dilated but there was some tapering at the site of anastomosis with the left pulmonary artery and in addition the aortic end was stenosed by the surgical ligature. Using the largest balloon available $(20 \mathrm{~mm} \times$ $12 \mathrm{~mm}$ ) the distal half of the shunt was filled by inflation of the balloon and so the shunt was occluded.

Embolisation using detachable balloons has been pioneered by White (Barth et al. ${ }^{3}$ ) who used ready made and prepared silicone balloons filled with isoosmotic contrast medium. A possible problem with such valved balloons is the occurrence of early deflation. This is not the case when the balloon, as in the Debrun system, is filled with silicone polymer. When positioned and inflated they provide permanent occlusion. A disadvantage is that each balloon has to be prepared and hand tied by the operator and this system is not to be recommended except to operators regularly involved with catheter occlusion therapy who are practised in this technique.

Balloon embolisation has been used as an alternative to surgery in pulmonary arteriovenous malformations $^{3}$ and in a coronary vascular anomaly. ${ }^{4}$ Of wider application is the role of embolisation as a adjunct to surgery, for example of systemic to pulmonary collateral arteries in the tetralogy of Fallot before corrective operation, using detachable balloons ${ }^{5}$ or gelfoam pieces and Gianturco coils. ${ }^{6}$

We thank Dr M Joseph and Mr P B Deverall for referring this patient.

\section{References}

1 Porstmann W, Wierny L, Warnke H, Gerstberger G, Romaniuk PA. Catheter closure of patent ductus arteriosus. Sixty-two cases treated without thoracotomy. Radiol Clin North Am 1971; 9: 203-18.

2 Culham JAG, Izukawa T, Burns JE, Freedom RM. Embolisation of a Blalock-Taussig shunt in a child. AfR 1981; 137: 413-5.

3 Barth KH, White RI, Jr, Kaufman SL, Terry PB, Roland JM. Embolotherapy of pulmonary arteriovenous malformations with detachable balloons. Radiology 1982; 142: 599-606.

4 Reidy JF, Sowton E, Ross DN. Transcatheter occlusion of coronary to bronchial anastomosis by a detachable balloon combined with angioplasty at same procedure. $\mathrm{Br}$ Heart F 1983; 49: 284-8.

5 Grinnell VS, Mehringer CM, Hieshima GB, Stanley P, Lurie PR. Transaortic occlusion of collateral arteries to the lung by detachable valved balloons in a patient with tetralogy of Fallot. Circulation 1982; 65: 1276-8.

6 Yamamoto S, Nozawa T, Aizawa T, Honda M, Mohri M. Transcatheter embolisation of bronchial collateral arteries prior to intracardiac operation for tetralogy of Fallot. F Thorac Cardiovasc Surg 1979; 78: 739-43.

Requests for reprints to Dr J F Reidy, Department of Radiology, Guy's Hospital, London SE1 9RT. 